Brazilian Journal
of Chemical
Engineering

\title{
DEEP REMOVAL OF 4,6- DIMETHYLDIBENZOTHIOPHENE FROM MODEL TRANSPORTATION DIESEL FUELS OVER REACTIVE ADSORBENT
}

\author{
Shengqiang Wang ${ }^{1 *}$, Ruicong Wang ${ }^{2}$ and Hongbing $\mathrm{Yu}^{1}$ \\ ${ }^{1}$ College of Environmental Science and Engineering, Nankai University, \\ Phone/Fax: 8622 23502756, Tianjin 300071, China. \\ E-mail: wshengq@nankai.edu.cn \\ ${ }^{2}$ Department of Chemistry, School of Science, Tianjin University, \\ Tianjin 300072, China.
}

(Submitted: May 10, 2011 ; Revised: December 21, 2011 ; Accepted: January 15, 2012)

\begin{abstract}
This paper presents a new reactive adsorbent used to effectively remove 4,6dimethyldibenzothiophene (4,6-DMDBT) from model transportation diesel fuels. This reactive adsorbent was composed of formaldehyde, phosphotungstic acid and mesoporous silica gel. The experiment was based on an assumed condensation reaction of 4,6-DMDBT with formaldehyde using phosphotungstic acid as catalyst in pore spaces. The effect of temperature and the amount of formaldehyde and phosphotungstic acid loaded on the substrate were investigated in a batch system. In the breakthrough experiment, three different model diesel fuels containing $1000 \mathrm{mg} / \mathrm{kg}$ 4,6-DMDBT were pumped through a fixed-bed reactor packed with reactive adsorbent at constant temperature and atmospheric pressure, respectively. The experimental results showed that sulfur-free model fuel was obtained at $80^{\circ} \mathrm{C}$ despite the presence of aromatics. The sulfur capacity of regenerated reactive adsorbent was almost totally recovered.

Keywords: Desulfurization; 4,6-Dimethyldibenzothiophene; Diesel Fuel; Phosphotungstic Acid; Reactive Adsorbent.
\end{abstract}

\section{INTRODUCTION}

The issue of atmospheric pollution and acid rain has drawn growing concern in recent years across the globe. Diesel-powered vehicles contribute to it in the form of exhaust gases, especially $\mathrm{SO}_{\mathrm{x}}$. The mandatory rules of law have been brought into effect in some developed countries on the aspect of the sulfur content in transportation diesel fuels. Thus, ultra-low sulfur fuels will become a tendency in the years to come. Removal of sulfur compounds is a crucial factor to fulfill the demand for ultra-low sulfur fuels. Thiophenic compounds in diesel fuels are the most difficult to be disposed of by traditional hydrodesulfurization (HDS) processes. Much work has been devoted to the removal of them from transportation fuels (Ito and Rob van Veen, 2006; Babich and Moulijn, 2003; Ma et al., 2002; Song, 2003; Breysse, et al., 2003).

Desulfurization technologies can be summarized as HDS and non-HDS. The former has been widely applied in the petrochemical industry. The latter needs to be further developed. HDS shows high capacity in removing thiols, sulfides, disulfides and partial thiophenes. However, some dibenzothiophenes and their derivative compounds such as 4,6-DMDBT, still remain after the HDS treatment because the alkyl groups at the 4- and/or 6-positions strongly inhibit the HDS of alkyl DBT compounds. The technology of non-HDS opens a new window for fuel desulfurization, such as oxidation, extraction, adsorption, alkylation and biodesulfurization. Among

*To whom correspondence should be addressed 
these, adsorption and selective oxidation (oxidationadsorption or oxidation-extraction) are the most promising due to their high selectivity. The advantage of selective oxidation desulfurization lies in its high selectivity aided by extraction or adsorption in the absence of hydrogen under mild conditions (Yang, et al., 2007, Ma, et al., 2007, Eber and Wasserscheid, 2004). Adsorption desulfurization has the advantage of high selectivity in the removal of thiophenic compounds from diesel fuels and can be performed at mild temperatures and atmospheric pressure. Adsorption desulfurization is subdivided into physical adsorption desulfurization and chemical reaction adsorption desulfurization. S-Zorb (Silica Zinc Oxide Removal Beused) (Gislason, 2002), a chemical adsorption desulfurization technology, requires the fuels to be gasified and fully contacted with adsorbent regardless of the quantity and purity of hydrogen. It is characterized by low pressure and high desulfurization efficiency. IRVAD (Irvine Robert Varraveto Adsorption Desulfurization) (Irvine, 1998) can effectively remove the sulfur in liquid fuels and satisfy the demand for ultra-low sulfur fuels. However, the adsorbent needs to be regenerated and recycled frequently. Hernández-Maldonado and Yang (2004) and Yang et al. (2003) reported that $\mathrm{Cu}$ (I)-Y surpasses $\mathrm{Ni}$ (II) and $\mathrm{Zn}$ (II) in terms of selectivity and breakthrough capacity, which reaches the level of $1.00 \%$ by weight However, the adsorption performance declines to a great extent when aromatics, oxidation and moisture are present in the fuels $(\mathrm{Li}$, et al., 2006). In terms of Song's SARS (selective adsorption for removing sulfur) technology (Song, 2003 ), the breakthrough capacity of $\mathrm{Ni} / \mathrm{SiO}_{2}-\mathrm{Al}_{2} \mathrm{O}_{3}$ reaches the level of $1.26 \%$ by weight, a slight improvement compared with $\mathrm{Cu}(\mathrm{I})-\mathrm{Y}$ of Yang et al. (2003). Therefore, the issues of sulfur selectivity and breakthrough capacity deserve more investigation. In addition, the regeneration capacity and recycling performance of the adsorbent requires improvement.

Our previous work demonstrated the potential feasibility of the condensation mechanism (Caesar and Sachanen, 1948) related to the removal of thiophenic compounds from transportation fuels (Wang et al., 2008; Zhou et al., 2008). The condensation reaction in the adsorbent between formaldehyde and 4,6-DMDBT, catalyzed by heteropoly acid, is assumed as the following: as shown in Scheme 1, an electrophilic substitution reaction occurs between protonated formaldehyde and 4,6-DMDBT to form hydroxymethyl 4,6DMDBT, which generates the corresponding carbocation under acidic condition, which continues to react with 4,6-DMDBT to yield polymers.
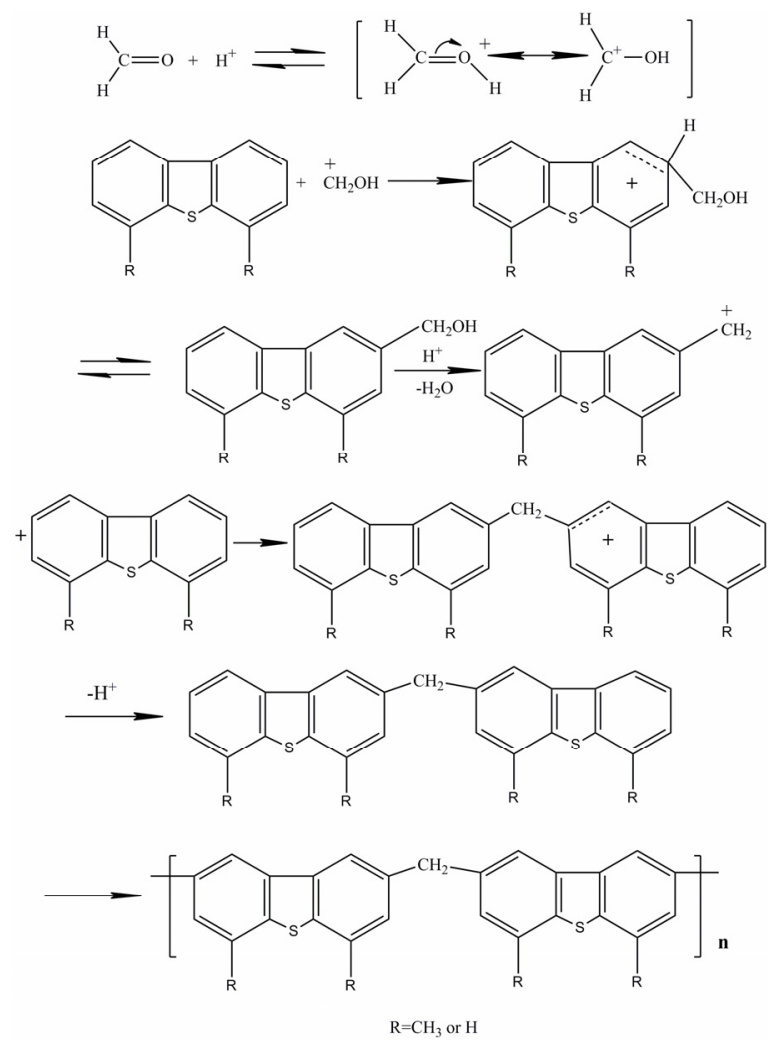

Scheme 1: The assumed mechanism of the condensation reaction occurring in the pore spaces for fuel desulfurization. 
The effectiveness of a porous adsorbent composed of substrate, formaldehyde and acid in desulfurization has been described in our previous work (Zhou et al., 2008). On the other hand, the high cost of the substrate hinders the use of reactive adsorbent in industrial applications. Thus, mesoporous silica gel was used as the substrate for loading formaldehyde and environmentally-friendly phosphotungstic acid (PTA) to reduce the cost of fuel desulfurization. The effect of aromatics on the sulfur conversion rate in a model diesel fuel was also studied.

\section{EXPERIMENTAL SECTION}

\section{Preparation of Reactive Adsorbent}

The reactive adsorbent was composed of $47.6 \%$ Silica Gel C (SGC), 33.3\% PTA and 19.1\% formaldehyde in mass proportion. The substrate SGC was impregnated with an $8 \%$ aqueous solution of PTA. The mixture of SGC $(0.154 \mathrm{~mm}-0.180 \mathrm{~mm})$ was stirred for an hour and dried at $100^{\circ} \mathrm{C}$ for 12 hours before being placed into the vacuum oven at $120^{\circ} \mathrm{C}$ for 5 hours. Thus, PTA/SGC came into being. Carried by nitrogen gas, formaldehyde vapor passed through a fixed bed filled with PTA/SGC at room temperature. We monitored the total weight of the reactive adsorbent before and after adsorbing formaldehyde vapor at different times until the proportion of the loaded formaldehyde vapor in the reactive adsorbent reached $19.1 \%$. SGC and PTA/SGC were characterized by using $\mathrm{N}_{2}$ adsorption-desorption isotherms at $-196^{\circ} \mathrm{C}$ in the High Pressure Adsorption Laboratory at Tianjin University.

\section{Reagents and Standards}

4,6-DMDBT of analysis grade was purchased from J\&K Chemical Ltd. (Beijing, PRC). Benzene, naphthalene and $\mathrm{n}$-dodecane of chromatographic grade were purchased from Kemiou Chemicals Center (Tianjin, PRC). PTA of analysis grade was purchased from Kewei Company (Tianjin, PRC). Formalin of analysis grade was purchased from Sanhe Chemicals (Yantai, PRC).

\section{Preparation of Fuels}

Thiophenic compounds are the main sulfur compounds remaining in transportation diesel fuels after HDS. 4,6-DMDBT was used to represent one of the refractory sulfur compounds in diesel fuels. In this work, three types of model fuels were prepared to examine the effect of aromatics on sulfur conversion as follows: (1): $100 \%$ n-dodecane, (2): $10 \%$ benzene and $80 \%$ n-dodecane plus 10\% naphthalene, (3): $90 \%$ benzene plus $10 \%$ naphthalene, which represented Aliphatic Fuels (ALF), Mixed Fuels (MXF) and Aromatic Fuels (ARF), respectively. The 4,6DMDBT concentration in all three model diesel fuels was $1000 \mathrm{mg} / \mathrm{kg}$ and the corresponding sulfur concentration was $151.0 \mathrm{mg} / \mathrm{kg}$. The sulfur concentration in model fuels was detected by a model WK-2D total sulfur analyzer. Details of the sulfur concentration analysis are given in our previous work (Wang et al., 2009).

\section{Batch Tests and Fixed Bed Breakthrough Experiments}

Batch tests were performed in a flask equipped with a thermostat, which provided circulating water to keep the temperature constant. In batch tests, the effect on desulfurization reaction rate of temperature and the amount of formaldehyde and PTA loaded on the substrate were investigated. The mixture of $2.1 \mathrm{~g}$ reactive adsorbent and $20 \mathrm{~g}$ 4,6-DMDBT model fuel in a $250 \mathrm{~mL}$ flask was stirred by a mixer for three hours. The sulfur concentration was detected every 15 minutes.

The breakthrough experiments were carried out in a vertical glass column (length $250 \mathrm{~mm}$, diameter $10 \mathrm{~mm}$ ) filled with the reactive adsorbent at constant temperature. The breakthrough capacity and saturation capacity of the adsorbent decreased slowly with increasing flow rate. On the other hand, much more time was needed to deal with the same volume of fuel if the flow rate decreased. The fuels were pumped up through the column in piston flow at the velocity of $0.5 \mathrm{~mL} / \mathrm{min}$. The contact time of the fuel with adsorbents was $30 \mathrm{~min}$. In terms of the breakthrough experimental data, a plot was made of the transient total sulfur concentration against cumulative fuel. The transient total sulfur concentration was normalized by the feed total sulfur concentration and cumulative fuel by the total substrate weight.

The following equations were employed to calculate the normalized breakthrough capacity $\mathrm{Q}_{\mathrm{b}}$ and the normalized saturation capacity $\mathrm{Q}_{\mathrm{s}}$.

$$
\mathrm{Q}_{\mathrm{b}}=\left(\frac{\mathrm{v} \rho \mathrm{x}_{\mathrm{i}}}{\mathrm{m}} \times \mathrm{t}_{\mathrm{b}} \times 100 \%\right)
$$


$\mathrm{Q}_{\mathrm{s}}=\left(\frac{\mathrm{v} \rho \mathrm{x}_{\mathrm{i}}}{\mathrm{m}}\right) \int_{0}^{\mathrm{t}_{\mathrm{s}}}\left[1-\frac{\mathrm{c}_{\mathrm{t}}}{\mathrm{c}_{\mathrm{i}}}\right] \mathrm{dt} \times 100 \%$

in which $\mathrm{Q}_{\mathrm{b}}$ and $\mathrm{Q}_{\mathrm{s}}$ are the normalized sulfur breakthrough and saturation capacities, respectively, in $\mathrm{wt} \%$; $v$ is the fuel volumetric flow rate in $\mathrm{mL} / \mathrm{min}$; $\rho$ is the fuel density in $\mathrm{g} / \mathrm{mL} ; c_{i}$ is the initial total sulfur concentration in the fuel in $\mathrm{mg} / \mathrm{kg}$; $\mathrm{m}$ is the total weight of substrate in the fixed bed in $g$; $c_{t}$ is the transient sulfur concentration at any time $t$ in $\mathrm{mg} / \mathrm{kg} ; \mathrm{x}_{\mathrm{i}}$ is the sulfur concentration in the model fuel by weight in $\%$; $t_{b}$ is the breakthrough time of sulfur in min; $t_{s}$ is the sulfur saturation time when $\mathrm{c}_{\mathrm{t}} / \mathrm{c}_{\mathrm{i}}=1$, in min.

\section{Regeneration and Recycle of Reactive Adsorbent}

Recycle work was performed when the reactive adsorbent was regenerated at the temperature of $400^{\circ} \mathrm{C}$ in air for three hours and formaldehyde adsorbed at room temperature. Then, the reactive adsorbent was used to remove 4,6-DMDBT from model transportation diesel fuels again.

\section{RESULTS AND DISCUSSION}

\section{Characterization of SGC and PTA/SGC}

Pore Structure Parameters of SGC and PTA/SGC are shown in Table 1 . The nitrogen adsorptiondesorption isotherms of SGC and PTA/SGC belong to type IV according to International Union of Pure and Applied Chemistry (IUPAC) classification, which confirmed the existence of a mesoporous character. Brunauer-Emmett-Teller (BET) was used to calculate the specific surface area on the basis of $\mathrm{N}_{2}$ adsorption isotherm curves (Brunauer, et al., 1938). The pore size distribution of SGC and PTA/SGC was calculated according to the BarrettJoyner-Helena (BJH) method (Barrett, et al., 1951). The specific surface area, pore volume and pore diameter of PTA/SGC decreased a great deal compared with those of SGC. However, the normalized pore diameter of PTA/SGC still corresponded to a mesoporous structure and was in the range of $2-50 \mathrm{~nm}$.

Table 1: Pore Structure Parameters of SGC and PTA/SGC.

\begin{tabular}{|l|c|c|c|}
\hline \multicolumn{1}{|c|}{ Name } & $\mathbf{S}_{\text {BET }} \mathbf{~ m}^{\mathbf{2}} / \mathbf{g}$ & $\mathbf{V}_{\text {pore }} \mathbf{~ c m}^{\mathbf{3}} / \mathbf{g}$ & $\mathbf{d}_{\text {norm }} \mathbf{~ n m}$ \\
\hline SGC & 315 & 0.88 & 5.6 \\
SGC after loading PTA & 136 & 0.52 & 3.8 \\
\hline
\end{tabular}

\section{Desulfurization of 4,6-DMDBT Model Fuels}

The batch tests and breakthrough experiments demonstrated the different and important roles that formaldehyde played in the reactive adsorbent. As shown in Figure 1, the desulfurization efficiency increased when the temperature ranged from $50^{\circ} \mathrm{C}$ to $80^{\circ} \mathrm{C}$. The presence of formaldehyde caused $100 \%$ removal of 4,6-DMDBT in $90 \mathrm{~min}$ at $80^{\circ} \mathrm{C}$ but only $8.14 \%$ in three hours in its absence. As can be seen from Figure 2, the highest reaction rate for desulfurization was shown when formaldehyde reached its maximum loading amount in the reactive adsorbent. Heteropoly acid also played important roles in the removal of 4,6-DMDBT from model diesel fuels. As shown in Figure 3, a higher desulfurization rate required more heteropoly acid, which resulted in the shrinkage of the reaction interface and pore volumes. The highest desulfurization rate appeared when the loading of heteropoly acid reached $0.7 \mathrm{~g}$ per unit mass substrate. The desulfurization rate of substrate benefits from the large specific surface area as well as pore diameter. As presented in Figure 4 and Figure 5, the sulfur capacities of the reactive adsorbent were closely related to formaldehyde as well as the type of fuel. The presence of formaldehyde in the adsorbent makes a difference to the desulfurization capacity, which results from the polymerization degree of the sulfurs. The sulfur breakthrough capacities decreased as follows: ALF $>$ MXF $>$ ARF due to the inhibitive effect of aromatics, which can competitively adsorb on active sites. However, they did not react with formaldehyde in the pores of the substrate at $80^{\circ} \mathrm{C}$ and atmospheric pressure. The batch test and breakthrough experiment demonstrated the different and important roles that heteropoly acid and formaldehyde play in the reactive adsorbent.

The regenerated condensation adsorbent was recycled two times in the desulfurization of MXF and the breakthrough curves are illustrated in Figure 6. As can be seen from Table 2, the sulfur breakthrough capacities of the regenerated adsorbent accounted for $98.4 \%, 97.8 \%$ of the original one and the sulfur saturation capacities recovered $98.8 \%, 97.4 \%$ of the original one, respectively. As is known, the aromatics have a great influence on the breakthrough capacity of adsorbent based on $\pi$-complexation in the desulfurization of transportation fuels containing 4,6DMDBT (Bhandari, et al., 2006). In our experiment, the sulfur breakthrough capacity per gram of substrate changed from $4.64 \mathrm{mg} \mathrm{S}$ to $4.59 \mathrm{mg} \mathrm{S}$ and $4.51 \mathrm{mg} \mathrm{S}$ when the aromatics went up from $0 \%$ to $20 \%$ to $100 \%$. It is evident that the aromatics had less of an adverse effect on the reactive adsorbent than on an adsorbent based on $\pi$-complexation in the desulfurization of ARF. 


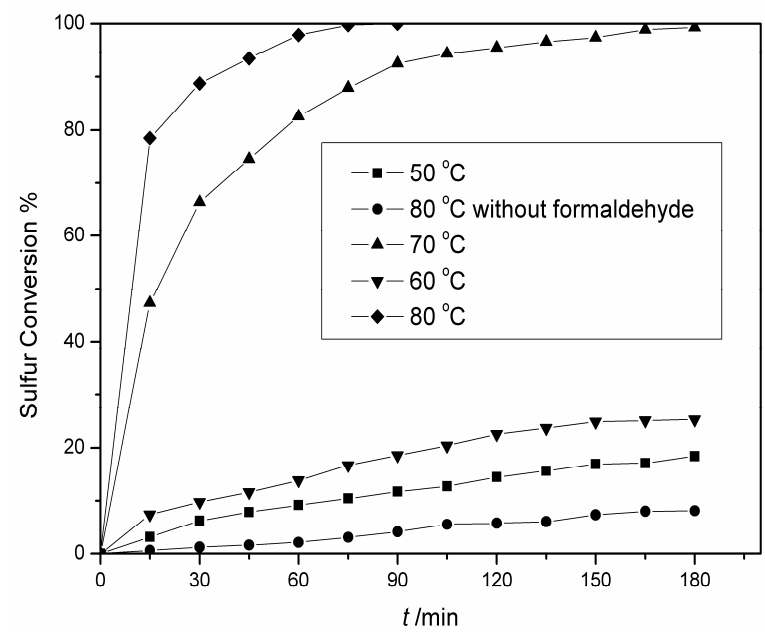

Figure 1: Effect of temperature on sulfur conversion over the reactive adsorbent.

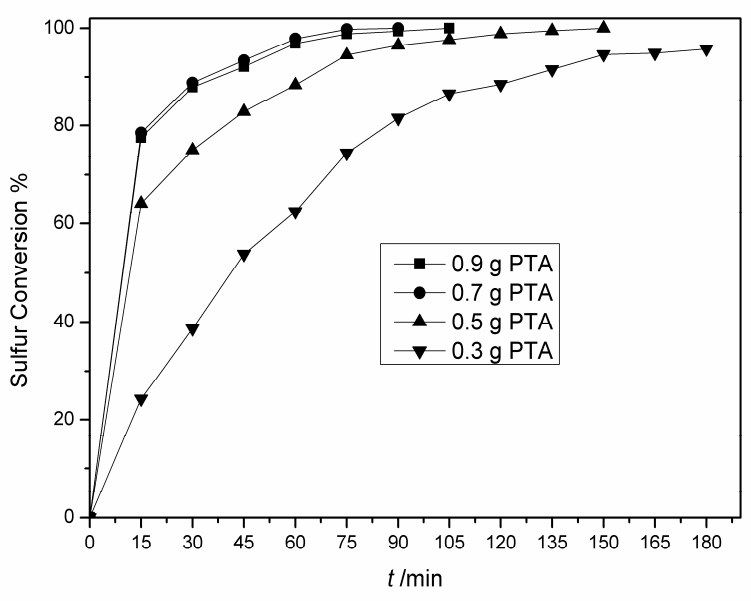

Figure 3: Effect of the amount of PTA loadedon the substrate on sulfur conversion at $80^{\circ} \mathrm{C}$.

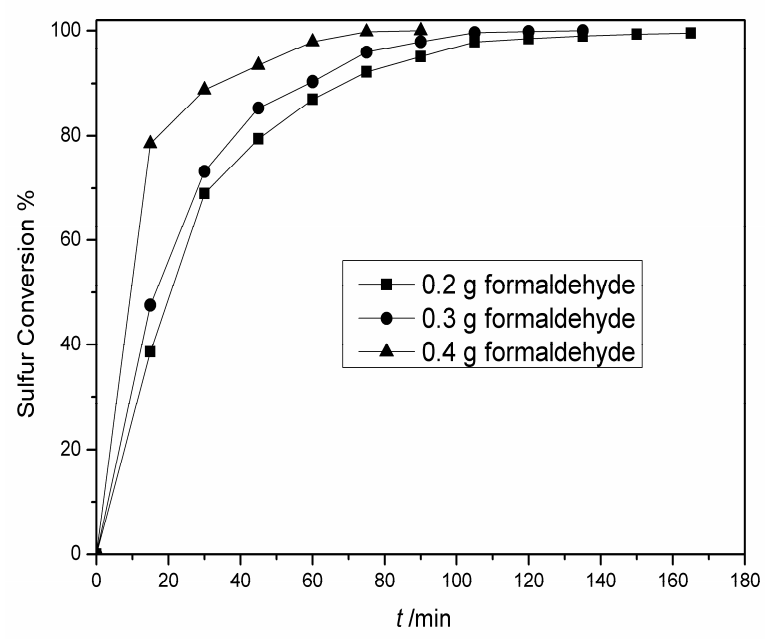

Figure 2: Effect of the amount of formaldehyde loaded on the substrate on sulfur conversion at $80^{\circ} \mathrm{C}$.

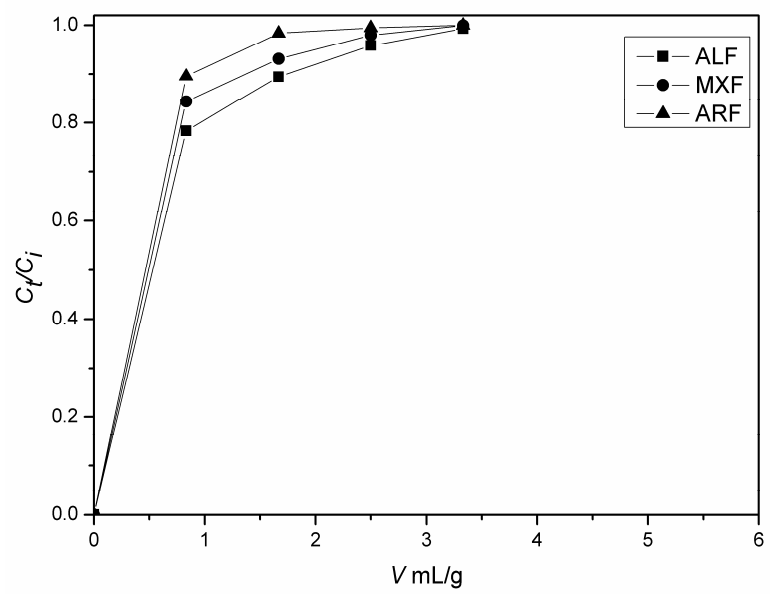

Figure 4: Breakthrough curves for three model fuels over PTA/SGC adsorbent without loading formaldehyde at $80^{\circ} \mathrm{C}$.

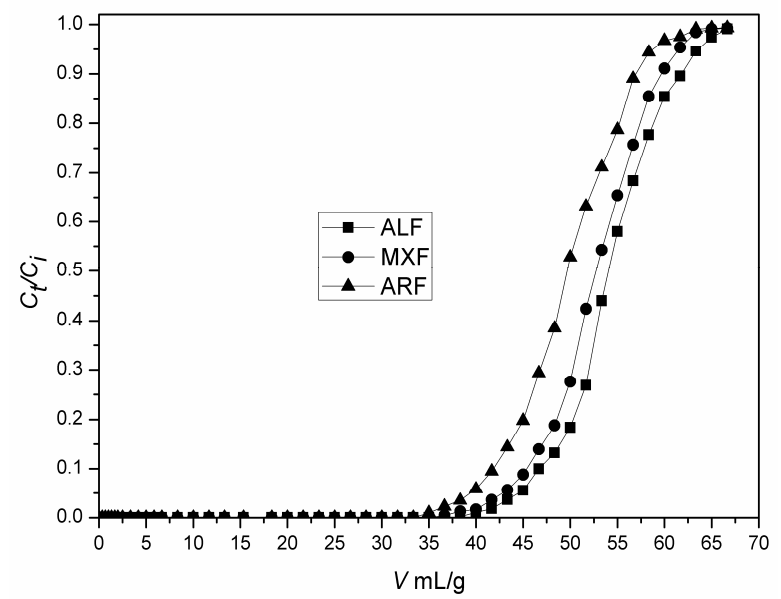

Figure 5: Breakthrough curves for three model fuels over reactive adsorbent at $80^{\circ} \mathrm{C}$. 


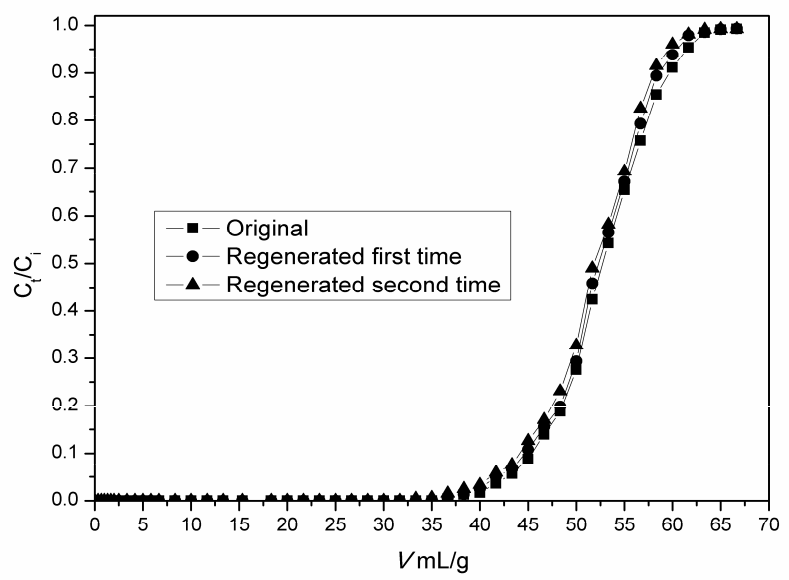

Figure 6: Breakthrough curves for MXF over the regenerated reactive adsorbent at $80^{\circ} \mathrm{C}$.

Table 2: Sulfur breakthrough and saturation capacities of the reactive adsorbents for 4,6-DMDBT model diesel fuels

\begin{tabular}{|l|c|c|c|c|r|}
\hline Name & $\begin{array}{c}\mathbf{4 , 6 - D M D B T} \\
\text { content } \mathbf{~ m g} / \mathbf{k g}\end{array}$ & $\begin{array}{c}\text { Sulfur content } \\
\mathbf{m g} / \mathbf{k g}\end{array}$ & $\begin{array}{c}\text { Fuel } \\
\text { type }\end{array}$ & $\begin{array}{c}\mathbf{Q}_{\mathbf{b}} \\
\mathbf{( \% )}\end{array}$ & $\begin{array}{c}\mathbf{Q}_{\mathbf{s}} \\
(\mathbf{\%})\end{array}$ \\
\hline PTA/SGC & 1000 & 151 & ALF & - & 0.0102 \\
PTA/SGC+HCHO & 1000 & 151 & ALF & 0.464 & 0.835 \\
PTA/SGC & 1000 & 151 & MXF & - & 0.0089 \\
PTA/SGC+HCHO & 1000 & 151 & MXF & 0.459 & 0.828 \\
PTA/SGC & 1000 & 151 & ARF & - & 0.0076 \\
PTA/SGC+HCHO & 1000 & 151 & ARF & 0.451 & 0.824 \\
Recycled first time & 1000 & 151 & MXF & 0.452 & 0.818 \\
Recycled second time & 1000 & 151 & MXF & 0.449 & 0.806 \\
\hline
\end{tabular}

Formaldehyde plays a key role in desulfurization. Both the desulfurization rate and the breakthrough capacity of the substrate benefit from the existence of formaldehyde, which expanded the polymerization degree of sulfur compound. The desulfurization of fuels is in accord with first order reaction dynamics, as been proved in our previous work (Zhou et al., 2008). At the initial stage, the assumed condensation reaction occurred in the pores, where the concentration of formaldehyde was in excess compared with that of 4,6DMDBT. The reaction continued with the continuous diffusion of 4,6-DMDBT molecules into the pores because of the concentration difference. The polymerization degree of sulfur compounds rose, while the concentration of formaldehyde and the reaction rate declined until all formaldehyde was consumed. The desulfurization rate of the adsorbent in the absence of formaldehyde was much less than that in the presence of it. The saturation of the adsorbent appeared soon after 4,6-DMDBT reached protonation equilibrium due to the interaction between the heteropoly acid and 4,6-DMDBT.

Heteropoly acids also produced a dramatic effect on the desulfurization rate. The rapidity of the reaction required more heteropoly acid, which resulted in a shrinkage of the specific surface area, pore diameter and pore volume. The corresponding reduction of adsorbed formaldehyde brought about a decrease of the desulfurization rate. Therefore, an optimum load of heteropoly acid was necessary.

Aromatics interfere with the assumed condensation reaction between 4,6-DMDBT and formaldehyde because of competitive adsorption on active sites between aromatics and 4,6-DMDBT diffused into the pores. Water produced by the condensation reaction in the pores can dilute the concentration of formaldehyde and protons. Consequently, the increase of the polymerization degree was inhibited and the reaction rate slowed down.

The sulfur breakthrough curves of regenerated reactive adsorbent agreed well with the original one and the decline of the capacity arose from the loss of catalyst in the recycling process, which can be avoided by combining desulfurization with regeneration in the same fixed-bed reactor.

The reactive adsorbent can efficiently remove 4,6-DMDBT from model transportation fuel while HDS technology is very effective for the removal of 
thiols, sulfides, disulfides and partial thiophenes. Thus, HDS and the reactive adsorbent are feasible and very promising technologies to satisfy the ultralow sulfur fuel demands.

\section{CONCLUSIONS}

This work has demonstrated that reactive adsorbent can effectively remove 4,6-DMDBT from model transportation fuels at mild temperatures and atmospheric pressure independent of aromatics. The feasibility of this approach was demonstrated by three model diesel fuels from which 4,6-DMDBT was removed. The objective of obtaining ultra-low sulfur model transportation diesel fuels was achieved. The capacity of the regenerated reactive adsorbent is almost completely recovered and the adsorbent still has high efficiency after being recycled two times. The reactive adsorbent will find more applications in deep desulfurization if it is linked with HDS technologies.

\section{ACKNOWLEDGMENT}

This work was supported by the National Natural Science Foundation of China (NO.21006053), the Fundamental Research Funds for the Central Universities (NO.65010551) and the Research Funds of Humanistic Social Science for Cyclic Economy and Low-Carbon Developments (NO.951004).

\section{NOMENCLATURE}

$\begin{array}{llr}c_{i} & \begin{array}{l}\text { the initial total sulfur } \\ \text { concentration in fuels } \\ \text { the transient sulfur } \\ c_{t}\end{array} & \mathrm{mg} / \mathrm{kg} \\ m & \begin{array}{l}\text { concentration at any time } \mathrm{mg} / \mathrm{kg} \\ \text { the total weight of substrate } \\ \text { in the fixed bed } \\ \text { the normalized sulfur } \\ \text { breakthrough capacity } \\ Q_{b}\end{array} & \mathrm{gt} \% \\ Q_{s} & \begin{array}{l}\text { the normalized sulfur } \\ \text { saturation capacity } \\ \text { the breakthrough time of } \\ t_{b}\end{array} & \mathrm{wt} \% \\ t_{s} & \begin{array}{l}\text { sulfur } \\ \text { the sulfur saturation time } \\ v\end{array} & \begin{array}{l}\text { when } c_{t} / c_{i}=1 \\ \text { the fuel volumetric flow rate } \\ \text { the sulfur concentration in } \\ \text { the fuels by weight } \\ \text { the fuel density }\end{array} \\ x_{i} & \mathrm{~min} \\ \rho & \mathrm{mL} / \mathrm{min} \\ & \end{array}$

\section{REFERENCES}

Babich, I. V., Moulijn, J. A., Science and technology of novel processes for deep desulfurization of oil refinery streams: A review. Fuel, 82, 607 (2003).

Barrett, E. P., Joyner, L. G., Halenda, P. P., The determination of pore volume and area distributions in porous substances. I. Computations from nitrogen isotherms. J. Am. Chem. Soc., 73, 373 (1951).

Bhandari, V. M., Ko, Chang Hyun, Park, Jung Geun, Desulfurization of diesel using ion-exchanged zeolites. Chemical Engineering Science, 61, 2599 (2006).

Breysse, M., Djega-Mariadassou, G., Pessayre, S., Deep desulfurization: reactions, catalysts and technological challenges. Catalysis Today, 84, 129 (2003).

Brunauer, S., Emmett, P. H., Teller, E. Adsorption of gases in multimolecular layers. J. Am. Chem. Soc., 60, 309 (1938).

Caesar, P. D., Sachanen, A. N., ThiopheneFormaldehyde Condensation. Ind. Eng. Chem., 40, (5), 922 (1948).

Dai Wei, Zhou Yaping, Wang Shengqiang, Desulfurization of transportation fuels targeting at removal of thiophene/benzothiophene. Fuel Proc. Technol., 89, 749 (2008).

Eber, J., Wasserscheid, P., Jess, A., Deep desulfurization of oil refinery streams by extraction with ionic liquids. Green Chem. 6, 316 (2004).

Gislason, J., Phillips sulfur-removal process nears commercialization. Oil Gas J. 99, 74 (2002).

Hernández-Maldonado, A. J., Yang, R. T., Desulfurization of transportation fuels by adsorption. Catal. Rev., 46, 111 (2004).

Irvine, R. L. US Patent 5,730,860 (1998).

Ito, Eri, Rob van Veen, J. A., On novel processes for removing sulphur from refinery streams. Catalysis Today, 116, 446 (2006).

Li Yingwei, Yang, F. H., Qi Gongshin, Yang, Ralph T., Effects of oxygenates and moisture on adsorptive desulfurization of liquid fuels with $\mathrm{Cu}(\mathrm{I}) \mathrm{Y}$ zeolite. Catalysis Today, 116, 512 (2006).

Ma Xiaoliang, Sun Lu, Song Chunshan, A new approach to deep desulfurization of gasoline, diesel fuel and jet fuel by selective adsorption for ultra-clean fuels and for fuel cell applications. Catalysis Today, 77, 107 (2002).

Ma Xiaoliang, Zhou Anning, Song Chunshan, A novel method for oxidative desulfurization of liquid hydrocarbon fuels based on catalytic oxidation using molecular oxygen coupled with selective adsorption. Catalysis Today, 123, 276 (2007). 
Song, C., An overview of new approaches to deep desulfurization for ultra-clean gasoline. diesel fuel and jet fuel. Catalysis Today, 86, 211 (2003).

Song, C., Ma, X., New design approaches to ultraclean diesel fuels by deep desulfurization and deep dearomatization. Applied Catalysis B 41, 207 (2003).

Wang Shengqiang, Zhou Li, Long Lei, Thiophene capture with silica gel loading formaldehyde and hydrochloric acid. Ind. Eng. Chem. Res., 47, 2356 (2008).

Wang Shengqiang, Zhou Li, Su Wei, Deep desulfurization of transportation fuels by characteristic reaction resided in adsorbents.
AIChE Journal, 55, 1872 (2009).

Yang Lina, Li Jian, Yuan Xingdong, Shen Jian, Qi Yutai, One step non-hydrodesulfurization of fuel oil: Catalyzed oxidation adsorption desulfurization over HPWA-SBA-15. Journal of Molecular Catalysis A: Chemical, 262, 114 (2007).

Yang, R. T., Hernandez-Maldonado, A. J., Yang, F. H., Desulfurization of transportation fuels with zeolites under ambient conditions. Science, 301, 79 (2003).

Zhou Li, Wang Shengqiang, Dai Wei, Intensified reaction of dilute thiophenes in nanoreactor. $\mathrm{J}$. Phys. Chem., A, 112, 1887 (2008). 